\title{
0 ASPECTO TENDENCIAL DA NEGATIVIDADE COMO LINHA DE FORÇA DA POESIA MODERNA EM DULCE MARÍA LOYNAZ
}

\section{THE TREND-BASED ASPECT OF NEGATIVITY AS POWER LINE OF MODERN POETRY IN DULCE MARÍA LOYNAZ'S WORKS}

Yoanky Cordero GÓMEZ ${ }^{1}$

RESUMO: Este trabalho, visando às análises da tendência da negatividade como linha de força da poesia moderna, propõe a discussão dessa problemática na obra da poeta Dulce María Loynaz, expoente da poesia lírica latino-americana, a partir de uma perspectiva crítica que considera a negação como elemento fundamental da obra da autora. Valemo-nos, especialmente, das contribuições que trouxe Hugo Friedrich em La estructura de la lírica moderna: de Baudelaire hasta nuestros días (1974). 0 trabalho demandou a revisão de alguns dos paradigmas da Modernidade, seus precursores e suas características principais.

Palavras-chave: Hugo Friedrich. Lírica moderna. Negatividade. Dulce María Loynaz.

${ }^{1}$ Doutorando em Letras. Instituto de Biociências, Letras e Ciências Exatas (IBILCE). Câmpus de São José do Rio Preto. Universidade Estadual Paulista Júlio de Mesquita Filho (UNESP). São Paulo. Brasil. Email: pitonizov@gmail.com 
GÓMEZ, Y. C. 0 aspecto tendencial da negatividade como linha de força da Poesia Moderna em Dulce María Loynaz

ABSTRACT: This paper, based on the analysis of the tendency of negativity as power line of modern poetry, proposes a discussion about the problem developed in the book " $\mathrm{La}$ estructura de la lírica moderna: de Baudelaire hasta nuestros días" (1974). This research also demanded the review of some of Modernity paradigms, its precursors and its main features.

Keywords: Hugo Friedrich. Modern lyricism. Negativity. Dulce María Loynaz.

\section{Introdução}

A poesia moderna, apesar de ser geralmente relacionada à produção lírica do século XX, tem sua grande fundamentação e desenvolvimento a partir da segunda metade do século XIX. Jean-Arthur Rimbaud, Paul Verlaine, Stéphane Mallarmé e, antes deles, o grande instaurador da lírica da Modernidade, Charles Baudelaire, lançam uma nova poesia, marcada pela negatividade. Com esses poetas franceses, a poesia passa, paradoxalmente, a ser fruto do cálculo e da fantasia (PAZ, 1982, p. 15-31), o que não acontecia antes porque a poesia precedente se definia sobre a base de valores ou atributos positivos, empregava uma linguagem concreta e sem acepções acessórias. A partir da proposta dos precursores da poesia moderna, os atributos líricos se transformam em negativos, referem-se cada vez menos ao conteúdo e cada vez mais à forma, como será possível observar no desenvolvimento de nosso trabalho. Segundo Friedrich (1974), esse tipo de poemas "no pretende ya medirse con lo que vulgarmente se llama realidad." ${ }^{2}$ A estética do mal, do feio e do grotesco, bem como a temática do caos, e o espanto do sujeito poético em relação ao mundo que o circunda, caracterizam suas produções. Entre as inovações desses autores, destacam-se a negação

\footnotetext{
${ }^{2}$ Não se pretende medir com o que vulgarmente se chama realidade. (FRIEDRICH, 1974, p. 23, tradução nossa).
} 
de toda herança literária, da realidade e da anormalidade, por meio da dissonância e da "escuridão" linguística.

A aplicação da questão da negatividade, tomada no sentido da ruptura com os cânones estéticos, que favorecem a novidade e o que é diferente, e o reflexo do repúdio à ordem aparente, a própria negação da ordem, nas obras que serão analisadas, justifica-se não somente por serem expoentes da poesia moderna, mas, também, por carregarem uma grande carga de condenações ou fragmentações do padrão históricoliterário vigente, uma poética comprometida e participante, nos moldes daquilo que se poderia chamar de poesia "de resistência" ${ }^{3}$, que tem como arma a palavra poética, sua (im)possibilidade de tudo dizer, sua (im)potência diante dos fatos, como aponta Osakabe:

[fluxo] puro que flui e não se controla, que é exatamente o que é: experiência que se dispõe perigosamente ao sujeito, ao convocá-lo para a consubstanciação única desse sonho, mas que se desfaz dramaticamente na sua própria precariedade. É a palavra providencialmente obscurecida pela sua própria impossibilidade. Por isso, um poema... morre e mata em nós o sentido de sua própria novidade. (OSAKABE, 2002, p.11)

Dessa forma, a seleção do poema : "Premonición” (Versos, 1920 1938) da poeta Dulce María Loynaz deve-se, fundamentalmente, ao fato de que por meio da leitura de seus poemas, perceberemos a predileção das autoras pela crítica sobre o mundo e sobre as coisas até chegar ao questionamento medular da poesia, interpelando, também a própria linguagem. "Nesse sentido, a poesia, muito menos que representação, seria o próprio fluxo que resultaria dessa aproximação [com a vida e com a morte]" (OSAKABE, 2002, p.99). Para além disso, cada poema desenvolve o caráter da negatividade de forma diferente, permitindo com isso uma melhor avaliação do processo, objeto da analise deste trabalho.

${ }^{3}$ Ibid., p.82. 
GÓMEZ, Y. C. 0 aspecto tendencial da negatividade como linha de força da Poesia Moderna em Dulce María Loynaz

Dulce María Loynaz : uma voz lírica do modernismo latinoamericano

Dulce María Loynaz teve um mito e uma literatura. Criou seu mito ao mesmo temo que a sua literatura: em ambos deixou marcas do seu caráter. Gostaria de insistir no final e entender esse seu caráter, sua consciência de solidão, como o maior aporte que têm nos feito: "Esse gesto de independência negada a se reconhecer separada dos outros, essa suficiência permitiu-lhe saber se reclamada e respeitada, além da permanência ativa das suas estrofes em nós". (ESPINOSA, 1961, p.29) ${ }^{4}$

Segundo César López (2011), a poesia de Dulce María Loynaz exerce uma fascinação que atrai, arrasta, assedia até conduzir a um dos mais atrativos e maiores perigos do oficio: a interpretação. E nesse instante de 'difícil acesso' poético, contra a interpretação: sua defesa. Ou, melhor, seu deleite trágico, dramático, agônico. A dúvida insondável, de toda criação verdadeira. De toda poesia.

Essa poesia cheia de limpidez e, paradoxalmente, obscuridade, parece escapulir-se, evadir-se para só se manter mais arraigada ao ser do leitor ou, pelo menos, para tentar um pouco mais de rigor, a uma zona iniludível e essencial do mesmo.

Em uma ocasião Loynaz, referindo-se a sua própria escritura poética, disse que "por la poesía damos el salto de la realidad visible a la invisible, el viaje alado y breve, capaz de salvar en su misma brevedad la distancia existente entre el mundo que nos rodea y el mundo que está más allá de nuestros cinco sentidos." (TORRES, 2011). ${ }^{5} 0$ que sua poesia transparece é uma subjetividade que, ao negar-se, afirma a sua identidade plasmada em suas abundantes negações, expressivas de uma contenda em que

\footnotetext{
${ }^{4}$ (ESPINOSA, 1961, p. 29, tradução nossa).

${ }^{5}$ Pela poesia damos o salto da realidade visível à invisível, a viagem asado e breve, capaz de salvar em sua mesma brevidade a distancia existente entre o mundo que nos rodeia y o mundo que está além dos nossos cinco sentidos (TORRES, 2011, tradução nossa. Disponível em: http://www.centroloynaz.cult.cu/index.php/category/articulos/ . Acesso em 02.agos. 2013)
} 
ressalta a espiritualidade feminina, reprimida, mas não passiva porque revela a intenção de chegar a ser.

\title{
O inegável do conteúdo negativo nos poema de Dulce María Loynaz
}

\author{
Alguien exprimió un zumo \\ de fruta negra en mi alma: \\ Quedé amarga y sombría \\ como niebla y retama. \\ Nadie toque mi pan, \\ nadie beba mi agua... \\ Dejadme sola todos.
}
Presiento que una cosa ancha y obscura y desolada viene sobre mí como la noche sobre la llanura...

O próprio título do poema - Premonición - associa-se ao caráter desses versos onde a autora revela-se - como pitonisa de mau augúrio em uma notável alusão negativa, cuja adesão é uma espécie proximidade especial que segundo Friedrich (1974) nos poetas modernos, convertese precisamente em afastamento intimo. 0 pressentimento do fatal que há de chegar (Presiento que una cosa ancha e obscura/ y desolada viene sobre mi) e a terrível dissociação da vida coletiva (Nadie toque mi pan,/ nadie beba mi água...) assim o manifestam. A negatividade destes versos é experimentada pelo eu-lírico por meio desse clima de escuridão, em uma poesia que se deixa lançar ao caos do inconsciente a novas experiências; uma poesia que distorce a "tessitura anímica" para atingir tanto a evasão do profundo "pré-pessoal" como também a transcendência vazia (FRIEDRICH, 1974, p.63)

Podemos dizer que essas relações aprofundam-se, nesse texto, por meio de vários aspetos: (i) a necessidade de solidão da poeta (Dejadme sola todos) como timoneiro de barco que navega no médio da tormenta, assumindo o fruto da experiência com o saldo nefasto que isso implica para a alma (Quedé amarga y sombria/ como niebla y retama), uma 
GÓMEZ, Y. C. 0 aspecto tendencial da negatividade como linha de força da Poesia Moderna em Dulce María Loynaz

questão que é indissolúvel, porque segundo Osakabe (2002, p.98) a sua formulação é simultânea à sua ocorrência, em ambos os sentidos, assim como é essa formulação quem confere existência a experiência, já que é impossível separar uma da outra. Exatamente como acontece com a poeta. Dessa maneira, a questão da negatividade, delineia tal poesia, impondo, de certa forma, uma resistência social; (ii) as referências à presença de elementos da natureza que reforçam essa escuridão (fruta negra/sombría como niebla/ uma cosa ancha y obscura/como la noche sobre la llanura) e que por meio da recorrência da adjetivação negativa (negra /amarga /sombria / obscura/ desolada) traduz no poema o sentido de proibição e renúncia estabelecido pela autora e voltado para o eu-lírico, para a própria linguagem poética, numa mistura de melancolia e perda de esperança.

Por outra parte, a menção duplicada do pronome indefinido ninguém (Nadie toque mi pan/ nadie beba mi agua) implica renúncia, pois proíbe o acesso dos outros. De maneira sugestiva, ao inicio do poema, torna-se indefinido também a autoria da ação desencadeante de todos estes maus (Alguien exprimió um zumo/de fruta negra em mi alma). Quando emerge esse pronome, chega carregado de incertezas, despersonalizado ou ambíguo, e é entendido como outro signo da negatividade intensificada por esse clima de dor; mais uma evidência de afastamento ao não garantir, com especificidade, o reconhecimento ou a relevância que pudesse ter esse ator. A negatividade se produz nesse caso especifico, e nos valemos de Friedrich (1974, p.226) para ilustrá-lo porque acontece "uma ruptura de contatos internos e externos entre o homem e o mundo e entre os homens entre si".

Dulce María usa a linguagem em função de vivificar e de explicitar sentimentos.

Es poesia capaz de tender el puente comunicativo autor-lector aun cuando no participemos de su aprenhensión filosóficareligiosa (...). Para llegar a esa comunicabilidad, requiere el 
poeta de uma tensión espiritual nada común, de um on dde comunicacón realmente universal(...) [LEMUS, 1986, p.186]

Daí que valoração semântica de cada frase brinda o interlocutor, clareza na mensagem enunciada apesar da notável escuridão que circunda esses versos; e cuja escuridão torna-se, segundo Friedrich (1974, p.29), pressuposto da sugestão lírica, “o poeta serve-se das palavras como teclas", desperta nelas forças que a linguagem cotidiana ignora. Tudo isso, fica reforçado no poema pelo emprego de alguns signos de pontuação (en mi alma:/ Quedé amarga y sombría) cujo uso contribui para certo efeito explicativo, que - embora não é característico da lírica moderna-, podem-se entender-se estes elementos no peso dramático da frase posterior. No caso da pontuação suspensiva (nadie beba mi agua.../como la noche sobre la llanura...) percebe-se por meio dela um distanciamento comunicativo, entretanto se realiza a extensão da proibição no primeiro exemplo, ou do território, no segundo, que podemos entender melhor valendo-nos de Friedrich (1974, p.111) "na lírica moderna não apenas a pessoa particular está excluída mais a humanidade dita normal também está". É valido reconhecer que entre os modernos, a poesia tem outro aspecto: deliberadamente troca o familiar pelo estranho e o próximo pelo remoto. Parece estar forçada a romper não somente o contato entre o homem e o mundo, senão também dos homens entre si.

Com a sutileza que caracteriza sua poesia, Dulce María Loynaz, oferece-nos uma despedida com marcas autenticadas pelos pesares. A negatividade é intensificada na poesia lírica de Dulce María pela presença dos temas da morte, da solidão, angústia, silêncio, sofrimento, que caracteriza o poema objeto de análise.

Esse poema transmite vários modos de sentir, toda uma emanação de pensamento que a autora extrai do mais íntimo do ser para expôlo ao leitor. Este compartilhar fraterno, quase uma confissão mística transformada em catarse emocional, leva um desnudamento do espírito 
GÓMEZ, Y. C. 0 aspecto tendencial da negatividade como linha de força da Poesia Moderna em Dulce María Loynaz

que a poeta aborda desde a entrega de cada imagem recriada, assim este poema simboliza a resignação de própria limitação (PORTUONDO, 1988, p.231).

Alguien exprimió un zumo

de fruta negra en mi alma:

A associação do sentimento de pena com a cor preta (fruta negra) derrama-se na obra poética de Dulce María, basta pensarmos em outros poemas, alguns incluídos dentro do mesmo livro, Versos (1920-1938) onde aparece como apoteose do manejo da obscuridade e a dor, o poema Vino Negro é um canto trágico e premonitório para a proclamação do silêncio e a contenção social como o único destino é auto-infligido. Estas intenções repetiram-se em outros versos (sombría como niebla - cosa ancha y obscura - como la noche)

A indefinição do pronome (Alguien - Alguém) dá uma abertura ao imaginário na procuração do gerador dessas ações funestas.

Quedé amarga y sombría

como niebla y retama.

Como produtos do dueto nos versos precedentes emergem o resultado da ação antes referida: escuridão, restos e dor são as imagens evocadas nesse fragmento, sensação reforçada pelo uso dos dois pontos, explicitando o vinculo entre a linha gramatical e de pensamento contido antes e depois dos signos. 0 uso da maiúscula (em mi alma: Quedé) doam forças a pessoa sobre a qual recaíram as qualidades negativas, apesar da omissão do sujeito. 0 uso do pretérito como conjugação verbal faz referência ao passado de desventura onde a voz lírica atual permanece presa. Sensação estimulada pelo emprego dos adjetivos que conformam 
uma analogia e contribuem para a recriação da atmosfera no trecho selecionado e no texto todo.

\section{Nadie toque mi pan, nadie beba mi agua... \\ Dejadme sola todos.}

Por detrás da confissão da experiência negativa tida pelo eu-lírico e as suas sequelas ao nível personificado, desata-se o comportamento por meio de severas interpelações que provocam o isolamento, produto dos efeitos da maldição. Apesar de que não há utilização dos signos de pontuação exclamativos, o enfático do verso resulta evidente pela aplicação do modo imperativo nas três expressões. Três comandos que não só representam um firme desejo, senão o férreo e o volitivo do caráter da poeta propriamente dito através do eu poético (Nadie toque mi pan - nadie beba mi água - Dejadme sola todos).

E é que o alheamento nesse caso denota um caráter punitivo, refletido por meio da menção da água e do pão, como únicos alimentos, estabelecendo-se um paralelo com os regimes de alimentação carcerária mais crua. Elementos que se reforçam na sentença final (Dejadme sola todos), em que se produz uma intenção manifesta da ruptura com o entorno, e por assim dizer, de negatividade. A referência ao pão não compartilhado (Nadie toque mi pan) aporta imagens de contraposição religiosa quando é precisamente o contrário da doutrina de Jesus; à noite antes de ser entregue às autoridades romanas que o acusavam e perseguiam, sentou-se com os seus discípulos, cortou um pão que todos comeram naquela última ceia, e pedindo que essa ação fosse feita sempre na sua memória. Daí que cada celebração eucarística é a herança do gesto de Cristo em sinal de fraternidade e amor intenso.

Por outro lado, o impedimento a de Outros beber a água (Nadie beba 
GÓMEZ, Y. C. 0 aspecto tendencial da negatividade como linha de força da Poesia Moderna em Dulce María Loynaz

miagua...), nos oferece imagens do ser(im)puro que se resiste ao contacto com os outros temendo a contaminação. Essa hipótese é só viável se a leitura parte da convicção mística que representa a água como símbolo de purificação, renascimento e nova vida. 0 encerramento da frase com a pontuação suspensiva permite a formulação de outros registros.

\section{Presiento que una cosa ancha y obscura y desolada viene sobre mí como la noche sobre la llanura...}

0 terceto que segue, marca o final do texto, outorga-lhe um tom de predição fatal que contrasta harmonicamente com a atmosfera lúgubre presente nos versos posteriores. A solidão também toma parte nesse poema, através da imagem literária que pinta a emoção (como la noche sobre la llanura): a noite pista sutil da solidão pela quietude dessas horas em que tudo parece dormir o sono eterno. Mais um convite nos faz a autora ao colocar os elementos de suspensão gramatical (...), convite que garante a polissemia do texto poético.

\section{Considerações finais}

Dulce María Loynaz é uma poeta que dialoga constantemente com o silêncio por meio das palavras e pela representação da voz; poderíamos afirmar que deseja o silêncio, se tivermosmos em conta as diversas e complexas significações que ele assume: ausência, falta, carência, elementos que estão estreitamente vinculados a com a presencia e a palavra trabalhada no seu discurso poético. Nesse propósito, o silêncio foi importante para dar sentido às palavras, às músicas e aos efeitos sonoros. Sem silêncio, a linguagem não significa.

Podemos dizer que esta poética do silencio é uma alternativa para quem, como a poeta, percorreu vastas zonas da linguagem. 0 silencio é a abstenção da fala ou da não-fala e mesmo nesse ponto aparece 
outra via, aquela onde o silencio acolhe a palavra latente, aquela que ainda está se para dizer, para escrever. Uma resposta pode ser pensada a partir de Orlandi (2007). Ela assinala que "o silêncio é um lugar de recuo necessário para que se possa significar, para que o sentido faça sentido. Além disso, o silêncio abre espaço para o movimento do sujeito. É o silêncio como horizonte, que atravessa as palavras, que existe entre elas, que indica que o sentido pode sempre ser outro ou ainda que aquilo que é o mais importante nunca se diz". Orlandi lembra que silêncio - na etimologia, silentium - significa mar profundo, e como para o mar, é na profundidade, no silêncio, que está o real do sentido.

\section{Referências bibliográficas}

BARBOSA, J. A. As ilusões da Modernidade. São Paulo: Perspectiva S.A, 1986.

ESPINOSA, N. Dulce María Loynaz, el ala oscura de su rebeldía. Mundo Hispánico, 14. Madrid, 1961.

FRIEDRICH, H. La estructura de la lírica moderna: de Baudelaire hasta nuestros días. Trad. Joan Petit. Barcelona: Seix Barral, 1974.

JIMÉNEZ PANESSO, D. Silva y la modernidad de lo imposible. In: Fin de siglo decadencia y modernidad: ensayos sobre el modernismo en Colombia. Segunda parte. Universidad Nacional de Colombia, Bogotá, 1994.

KRISTEVA, J. Poesía y negatividad. Semiótica 2. 2 ed. Madrid: Fundamentos España. , 1981.

LÓPEZ, César. Poesía Dulce María Loynaz, Prólogo. La Habana: Letras Cubanas. Cuba, 2011, p. VI. 
GÓMEZ, Y. C. 0 aspecto tendencial da negatividade como linha de força da Poesia Moderna em Dulce María Loynaz

LÓPEZ, K. A. Figuras de lo melancólico: la petrificación del sujeto y la vitalidad de las cosas del mundo. Trabajo final de Licenciatura. Facultad de Filosofía y Humanidades. Escuela de Letras. Universidad Nacional de Córdoba, 2010, p. 35.

MIRANDA, P. Lo espacial en la poesía de vanguardistas chilenos y en Ecuatorial de Huidobro. Acta Literaria, n. 44, I Seminario. Santiago de Chile, 2012, p.113.

NÚÑEZ GARCiA; X. F. Silencio y soledad en la poesía de Dulce María Loynaz. Islas, n. 42. La Habana: Universitaria, 2000, p. 12. ORTEGA, José. La aventura poética de Pablo Picasso. La Palabra y el Hombre. n.90. Universidad Veracruzana. México, 1994.

SIMÓN, P. Premonición. In: Dulce María Loynaz, Poemas escogidos. Madrid: Visor Poesía. España, 1993, p. 27.

LEMUS, V., "En mi verso soy libre: él es mi mar", in SIMÓN, P. Dulce María Loynaz, Valoración múltiple. Casa de las América. La Habana: Letras Cubanas. Cuba, 1991, p. 182-193.

PORTUONDO, J. A."Voluntad de estilo en Dulce María Loynaz", in SIMÓN, P. Dulce María Loynaz, Valoración múltiple. Casa de las América. La Habana: Letras Cubanas. Cuba, 1991, p. 222226.

TORRES RUISÁNCHEZ, C. M. La prosa de Dulce María Loynaz: camino poético hacia otros mundos. In: Artículos del Portal Web del Centro Cultural Dulce María Loynaz. La Habana, 2011. Disponível em: http://www.centroloynaz.cult.cu/index.php/category/ articulos/. Acesso em 02.ago.2013. 